\title{
Primary onychomycosis with granulomatous Tinea faciei
}

\section{Authors}

Georgi Tchernev ${ }^{1}$

José Carlos Cardoso ${ }^{2}$

Musheera Mohammad $\mathrm{Ali}^{3}$

James W Patterson ${ }^{4}$

${ }^{1}$ Department of

Dermatology and

Venerology, Trakian

University, Medical

Faculty,Armeiska street

11, 6000 Stara Zagora,

Bulgaria.

${ }^{2}$ Dermatology and

Venerology Department,

University Hospital of

Coimbra Praceta Pinto,

3000075 Coimbra,

Portugal.

${ }^{3}$ Department of

Dermatology and

Venereology, Cardiff

University, Cardiff, United

Kingdom.

${ }^{4}$ Division of Surgical

Pathology \&

Cytopathology, Room

3018, University of Virginia

Hospital. University

of Virginia Health

System 1215 Lee Street,

Charlottesville, VA, USA.
Submitted on: 08/15/2010

Approved on: 08/17/2010

\section{Correspondence to:}

Associated Prof Dr Georgi

Tchernev MD, PhD

Department of

Dermatology and

Venerology,

Trakian Medical

University of Stara

Zagora

Zip code 6000

Medical faculty, 11

Armeiska Street, Stara

Zagora, Bulgaria

Phone: 00359-885-588424

Email: georgi_tchernev@

yahoo.de

We declare no conflict of interest.

\section{TO THE EDITOR}

We report a 67-year-old male who was referred to us due to subfebrile temperatures, nocturnal diaphoresis and painful lesions on his left cheek. His past medical history revealed that he has severe type 1 diabetes mellitus, hypertension, hepatitis A and pulmonary tuberculosis. The patient was under topical therapy with ciclopirox olamine lacquer for onychomycosis of the toenails of both feet.

Clinical examination disclosed violet to dark red confluent plaques involving the left cheek and neck (Figure 1). Previous therapy with doxycycline and flucloxacillin was ineffective. Due to lack of response to therapy and associated problems, clinical investigations were performed in order to exclude systemic tuberculosis and other systemic disorders, to arrive at the diagnosis and start appropriate therapy.

Direct microscopic examination of scrapings obtained from the left cheek revealed the presence of fungal elements, while those from the toenails and beard were negative. Fungal cultures demonstrated Trichophyton rubrum from the left cheek, beard and toenails. Histological sections showed multinucleate giant cells with fungal elements within the cytoplasm.

There were no abnormalities in lymphocyte subpopulations, and serum or urine protein electrophoresis was normal. HIV, p-ANCA, c-ANCA and ANA were all negative. PCR in lesional skin revealed no Mycobacterium tuberculosis DNA, and Ziehl-Neelsen staining was also negative. After similar microbiologic investigations from sputum sample, as well as pulmonary imaging studies, the possibility of active tuberculosis was ruled out.

After starting systemic therapy with itraconazole $100 \mathrm{mg}$ twice a day for 14 days (4 cycles) and local therapy with solution of $3 \%$ brilliant green in combination with octenidine dihydrochloride solution, full remission was achieved.

Figure 1: Hemorrhagic, confluent plaques and papules in the area of the left cheek and neck present over 2 months. 
Trichophyton rubrum and Trichophyton violaceum are the most common anthropophilic dermatophytes responsible for Tinea barbae. ${ }^{1,2}$ We present here a case of onychomycosis with granulomatous form of Tinea barbae. Trichophyton rubrum was isolated both from the toenails and the lesions of the neck. Onychomycosis was present for over 2 years, but lesions of the left cheek and the neck for only about 2 months. PAS staining is mandatory in cases in which a cutaneous granulomatous infiltrate is observed on histology. Ziehl-Neelsen staining and PCR amplification in the tissue helped excluding cutaneous tuberculosis.

Painful papules and nodules with tendency to confluence could suggest the diagnosis of Wegener's granulomatosis, which makes the serological determination of c-ANCA and histopathological analysis mandatory. ${ }^{3}$ Attention should be paid to the fact that in a high percentage of patients (up to $40 \%$ ) this result can be negative. ${ }^{3}$

Our case is interesting due to the presence of disseminated Trichophyton rubrum infection despite the lack of evidence of serious immunodeficiency, which suggests infection/reinfection due to a permanent contact with infected animals/humans from one side ${ }^{4,5}$ or autoinnoculation in the context of possible deregulations in local immune defense mechanisms of the skin. ${ }^{4,5}$

Treatment of fungal skin infections, such as Tinea pedis or onychomycosis, may prevent infection spread, highlighting the importance of treating the primary focus of infection.

[Braz J Infect Dis 2010;14(5):546-547]@Elsevier Editora Ltda.

\section{REFERENCES}

1. Beswick SJ, Das S, Lawrence CM, Tan BB. Kerion formation due to Trichophyton rubrum. Br J Dermatol Nov 1999; 14:953-4.

2. Glaser DA, Riordan AT. Images in clinical medicine. Tinea barbae: man and beast. N Engl J Med 1998;338:735.

3. Orfanos CE, Garbe C. Wegener-Granulomatose. In: Orfanos CE, Garbe C, (eds). Therapie der Hautkrankheiten. 2 Aufl. Berlin: Springer Verlag; 2002. pp. 505-7.
4. Orfanos CE, Garbe C. Sonstige oberflächliche Pilzinfektionen. In: Orfanos CE, Garbe C, editors. Therapie der Hautkrankheiten. 2 Aufl. Berlin: Springer Verlag; 2002. pp. 41-3.

5. Braun Falco O, Plewig G, Wolff HH. Dermatomykosen. In: Braun Falco O, Plewig G, Wolff HH: Dermatologie und Venerologie. 4th ed. Berlin: Walter de Gruyter; 1997. pp. 279-317. 